\title{
Strategic planning in higher education
}

\author{
By Barbara B. Moran \\ Assistant Professor, School of Library Science \\ University of North Carolina at Chapel Hill
}

\section{Stratagems for survival in the 80's.}

\section{S} first used primarily in business and industry, has slowly but steadily been transforming the way colleges and universities cope with an uncertain future. Since the late 1970s, the practice of strategic planning has become fairly widespread in American institutions of higher education. This article will explain how strategic planning differs from conventional planning, how it is used in colleges and universities, and how it can be used to advantage by academic libraries.

\section{Background}

Although colleges and universities have paid lip service to the importance of planning for many years, little effective planning actually went on. Many administrators thought that planning for the future was a waste of time. Patterns and practices were established to take care of the day-to-day operations of the institution, and most long-range changes were made in reaction to events rather than in anticipation of changing circumstances.

Some colleges and universities did attempt to do some long-range planning that often resulted in a so-called "master plan" for an institution or an entire system of higher education. Unfortunately changing circumstances usually made the detailed forecasts in these documents obsolete very quickly, and most master plans were left to gather dust on an administrator's bookshelf.

This lack of planning produced no serious reaction as long as resources for higher education were plentiful and student enrollment increased each year. During the 30 years following World War II, there were both enough resources and students available to keep academia prosperous.

However, during the 1970s circumstances became less auspicious. Federal funding designated for higher education was cut back. Inflation had a devastating impact on the already tightened budgets of colleges and universities. Changes in demographic patterns resulted in a shrinking number of 18-22 year olds, and competition within higher education for funds and students intensified. It soon became apparent that many colleges and universities were not going to survive in this straitened financial climate unless they set priorities and developed strategies for reacting to this changing and competitive environment.

The strategic planning process can help an institution cope with an uncertain future environment. Its dual purpose is to relate an institution to its environment and to provide unity and direction to all its activities. ' The central focus of strategic planning is to develop a good match between institutional activities and environmental demands.

Strategic planning requires that an institution become active rather than passive. As George Keller describes it:

“To think strategically is to look intensely at contemporary history and your institution's place in it and work out a planning process that actively confronts the historical movement, overcomes it, gets on top of it, or seizes the opportunities latent in it. A campus with an academic strategy has a battle

${ }^{1}$ Robert C. Shirley, "Identifying the Levels of Strategy for a College or University," Long Range Planning 16 (June 1983): 93. 
plan to get stronger or better in the teeth of historical conditions. It reads the face of history-or, to change disciplines the ecological environmentskillfully and then devises a scheme to survive in it and transcend it. With an academic strategy a college or university leaves the passive mendicant order and becomes an active knight-errant."2

Strategic planners must decide where they want their institution to be in a given number of years, and then choose the strategies necessary to allow them to reach this goal. As a part of this process, resources are deliberately concentrated in highly goal-oriented programs.

\section{Steps in planning}

How does a college or university begin to plan strategically? According to Kotler and Murphy, strategic planning typically involves six stages.

The first step is to analyze the environment. Institutional strategies must be modified as the environment changes. The major questions to be asked in this step are: What are the major trends in the environment? What are the implications of these trends for the institution? What are the most significant opportunities and threats? The aim of this analysis is to document the most significant trends around which the organization must formulate its future goals, strategies, and structures. Careful attention should be paid to both environmental threats and opportunities. Threats are those factors that can lead to the stagnation, decline, or death of an institution or one of its programs unless corrective action is taken (such as the declining pool of available students). Opportunities are areas in which a particular organization is likely to enjoy competitive advantages.

The next step is to conduct a resource analysis. Here an institution should identify its distinctive competencies - those areas where the organization is especially strong - as well as the resources that it lacks. In evaluating its strengths and weaknesses an institution should go beyond its own perceptions and learn how the institution is perceived by its key publics-faculty, students, parents, alumni, contracting organizations, and others.

Step three is to examine basic institutional objectives and goals. Because of the analyses performed in the last two steps, it may be necessary to reformulate existing goals and objectives. An institution should specify both what its current goals are and what its goals should be, so that it will have a clear picture of what it wants to be like at the end of the planning period.

Next, the college or university must determine strategies to help it achieve its goals. This involves two tasks. The first is to develop an academic portfolin strategy. This portfolio provides a systematic approach to examining academic programs by

${ }^{2}$ George Keller, Academic Strategy: The Management Revolution in Higher Education (Baltimore: Johns Hopkins, 1983), pp. 143-144. looking at both quality and the centrality of the program to the institution. The second is to evaluate the market viability or demand for each program. On the basis of these evaluations, decisions can be made to reduce or eliminate programs and develop others.

Fifth, an institution should develop a product/ marketing opportunity strategy by deciding what new programs it should add and into what markets it should expand in order to maintain or increase future enrollment. This allows the administration to imagine new options in a systematic way, to make decisions about which should be adopted, and to develop a marketing strategy for any new options that might be developed.

The last step is to design or improve the systems the institution will need to develop and carry out the strategies chosen to help it achieve its goals. ${ }^{3}$

The major purpose of all these steps is to allow an institution to attain or maintain a strategic advantage over its competitors by first selecting the appropriate areas to emphasize, determining the shrewdest courses of action, and then making the changes necessary to reach its goals.

\section{How it's different}

The differences between strategic planning and conventional planning are immediately apparent. First, strategic planning focuses on the institution's environment more than traditional planning. Traditional planners usually view an institution as a closed system while strategic planners adopt an "open-system" model, recognizing that many key elements that determine the long-range destiny of an organization occur in the outside environment.

Second, the time orientation in strategic planning is short-range and medium-range. Unlike conventional long-range planners who plan for the distant future, strategic planners feel that long range plans will almost always fail because environmental conditions change rapidly and plans become obsolete. Strategic planners concentrate on short-range and medium-range issues and usually work within a time-frame of three to five years. Unlike typical long-range plans, strategic plans are never "written on stone" but are continuously updated as the need arises.

A third difference is that strategic planning is undertaken with the awareness that there are competitors in the field, and that individual institutions will need to plan in order to be in the most advantageous position. There has always been competition in higher education, but for many years this competition was masked because of the increasing student enrollment. The competition is out in the open now, and institutions must be aware of the competitive nature of the field in order to survive.

A fourth difference is that strategic planning is

${ }^{3}$ Philip Kotler \& Patrick E. Murphy, "Strategic Planning for Higher Education," Journal of Higher Education 52 (Sept-Oct. 1981): 473-487. 
primarily the task of top managers rather than individuals in a planning office or on a committee. Only top level managers have the power required to make the necessary decisions and then implement them. Of course, in colleges or universities, the opinions and advice of all constituencies should be solicited before the plans are made. Nevertheless the planning itself is done by senior administrators and is a "top-down" rather than "bottom-up" process of planning.

Finally, instead of focusing on the nuts and bolts of everday operational issues, strategic planning deals with the larger issues, concentrating on the institution's purpose and missions, its relationship to its environment, and its share of the market. The emphasis in strategic planning is always on the "big picture."

\section{Library applications}

Colleges and universities which are using strategic planning methods have found them useful for developing systematic and market-oriented plans to meet an uncertain future. Institutions that are actively planning for the future are faring better than those which are passively awaiting a future that may never arrive for them. If strategic planning is working well in colleges and universities, could the libraries in these institutions also benefit from strategic planning?

To date little information has been available about the use of strategic planning in academic libraries. However, a recent Association of Research Libraries SPEC Kit on strategic planning reported that a survey of 30 ARL members' planning efforts revealed the existence of some library plans with strategic features:

"Most documents are descriptive of library strengths and weaknesses. . . . They address questions of what the library does especially well, what the library does that no other department can do, and which user groups represent primary client groups. Second, these plans contain considerable speculation about the future prospects of research libraries. While these speculations tend to be more general than a formal scenario, they do attempt to anticipate trends... and look at the broader context in which libraries perform, including economic development, university prospects, and political constraints. Third, the plans identify specific priorities and define the costs of desired courses of action. Finally the documents...suggest an activist posture on the part of library leadership in shaping the views and actions of the university community."

How can academic library administrators benefit by adopting strategic planning methods? Sev-

${ }^{4}$ J. Victor Baldridge \& Patricia H. Okimi, "Strategic Planning in Higher Education: New Tool or New Gimmick?" AAHE Bulletin 35 (October 1982): $17-18$

${ }^{5}$ Association of Research Libraries, Strategic Planning in ARL Libraries, Spec Flyer 108 (Washington D.C.: ARL, October, 1984), pp. i-ii. eral elements in the strategic planning process are especially relevant to libraries. For instance, the emphasis on identifying programs with special advantages or opportunities and concentrating resources in these programs could benefit many libraries. Too many libraries have begun new programs without ending old ones and their resources have been spread too thinly. As a result, none of the programs are really effective. Strategic planning would force a library to identify those areas in which it has a competitive advantage and let it concentrate its resources there.

The strategic planning emphasis on studying the external environment and attempting to identify competitors would also benefit most libraries. Librarians must monitor environmental change and become more proactive and entrepreneurial if the library is to be funded at a rate sufficient to allow it to introduce programs made necessary by the electronic revolution. Many writers have commented that the computer center is likely to be the library's most formidable competitor for funds in the near future, but how many libraries are now planning to meet this competition?

In an era when fundamental changes are occurring in academic libraries, the strategic planning focus on such larger issues as institutional mission and goals would be especially helpful to library administrators. Librarians must move quickly and decisively to take advantage of the opportunities presented, and strategic planning provides a means to develop a better sense of direction for the library's future. Questions such as "What business is the library in?", "What business do we want it to be in?", and "How can we get there from here?" could all be addressed more successfully by strategic planning than by any other type of planning.

As academic librarians try to stay abreast of the fast changes occurring both in the library itself and in its external environment, they will find they can no longer afford to ignore the advantages that strategic planning can provide in establishing a direction for the library's future. As Davis wrote:

"In the placid world of traditional librarianship, strategic planning was an unnecessary and indeed alien idea connoting conniving at its worst extreme. The library was meant to be carried wherever the satisfaction of the user needs took it. In the turbulent, resource-scarce environment of contemporary librarianship, strategic planning becomes indispensable.",

As academic libraries become aware of the benefits of strategic planning, they, like their parent institutions, will begin to utilize this method of planning to position themselves more advantageously to meet the future in a changing and unstable environment.

${ }^{6}$ Peter Davis, "Libraries at the Turning Point: Issues in Proactive Planning," Journal of Library Administration l (Summer 1980): 15. 


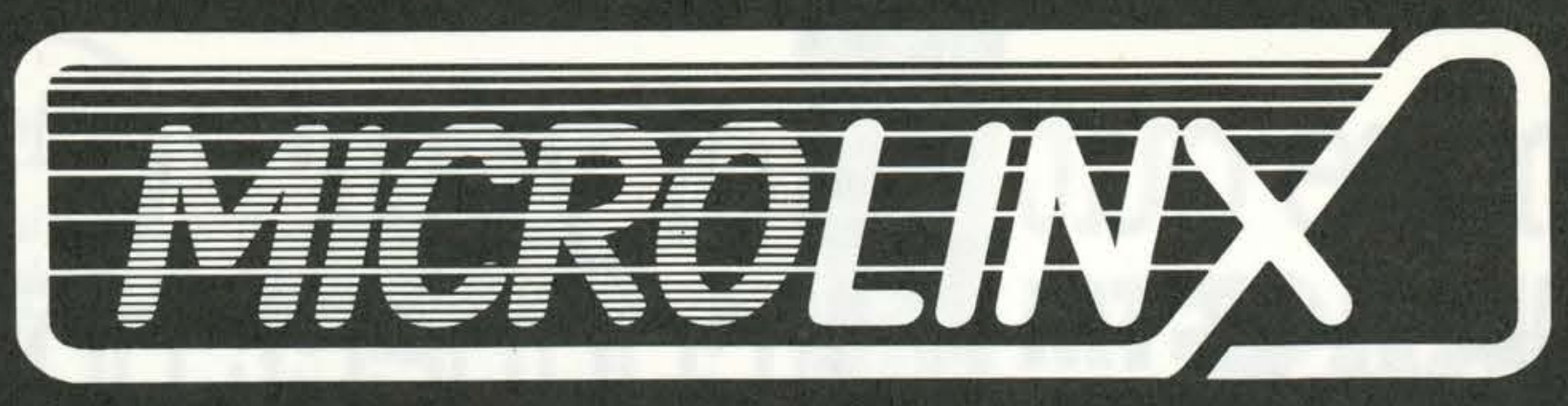

\section{A Microcomputer Based Serials Control System}

Call Us.

800-225-6055 (toll free) 617-329-3350 (collect) 


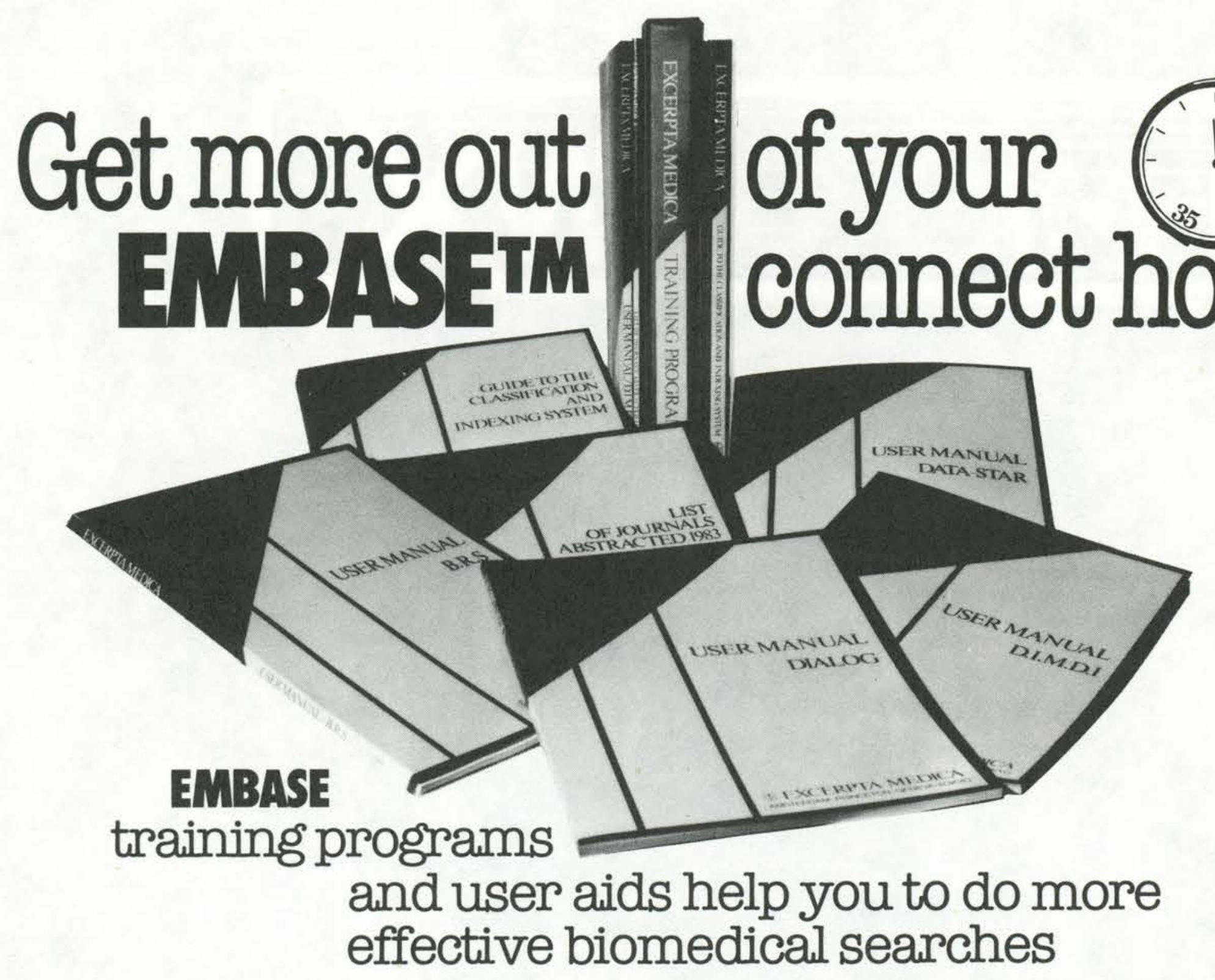

FRझF Training Programs:
OFxcerpta Medica offers over
200 training seminars world-
wide every year.
Training Program I provides
an introduction to EMBASE, its
coverage, indexing policy and
types of literature covered.
Participants in the USA \&े
Canada are entitled to 6CE
credits.
Training Program II
(advanced) is intended for

those who have already attended T.P.I. This Program elaborates on EMBASE indexing policy, classifications and specific search formulation. Participants in the USA \&? Canada are entitled to $4.8 \mathrm{CE}$ credits.

\section{USHR ATDS}

- Fxcerpta Medica's Guide to the Classification and Indexing System, provides a complete listing of all classification terms and secondary concepts.

- Fxcerpta Medica's Iist of Journals Abstracted provides a complete listing of approximately 4500 joumals screened for EMBASE.

-User Manuals: EMBASE on Dialog - EMBASE on DIMDI EMBASE On Data Star - EMBASE on BRS.

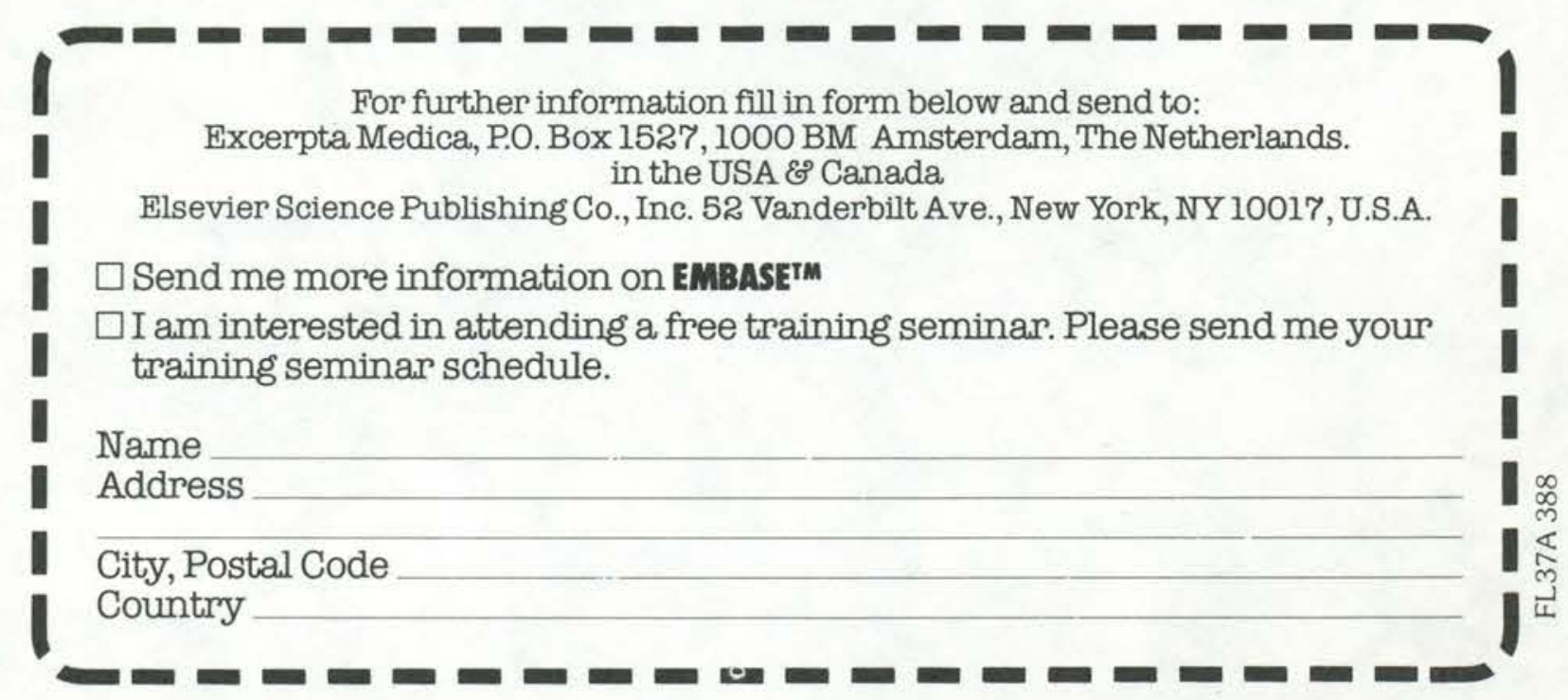

EMBasE'm is a trade name of Elsevier Science Publishers BV/Excerpta Medica. 